\title{
Altered maturation of peripheral blood dendritic cells in patients with breast cancer
}

\author{
S Della Bella ${ }^{*}$, , M Gennaro' ${ }^{2}$ M Vaccari', C Ferraris'², S Nicola', A Riva', M Clerici', M Greco ${ }^{2}$ and ML Villa' \\ 'Dipartimento di Scienze e Tecnologie Biomediche, Cattedra di Immunologia, Università degli Studi di Milano, LITA Segrate, via F.lli Cervi 93, Segrate (MI) \\ 20090, Italy; ${ }^{2}$ Unità Operativa di Senologia, Istituto Nazionale per lo Studio e la Cura dei Tumori, via Venezian I, Milano 20133, Italy; ${ }^{3}$ Dipartimento di \\ Scienze Precliniche, Cattedra di Immunologia, Università degli Studi di Milano, LITA Vialba, Ospedale Sacco, via GB Grassi 74, Milano 20I56, Italy
}

\begin{abstract}
Tumours have at least two mechanisms that can alter dendritic cell (DC) maturation and function. The first affects the ability of haematopoietic progenitors to differentiate into functional DCs; the second affects their differentiation from CDI4+ monocytes, promoting an early but dysfunctional maturation. The aim of this study was to evaluate the in vivo relevance of these pathways in breast cancer patients. For this purpose, 53 patients with invasive breast cancer were compared to 68 healthy controls. To avoid isolation or culture procedures for enrichment of DCs, analyses were directly performed by flow cytometry on whole-blood samples. The expression of surface antigens and intracellular accumulation of regulatory cytokines upon LPS stimulation were evaluated. The number of DCs, and in particular of the myeloid subpopulation, was markedly reduced in cancer patients $(P<0.00 \mathrm{I})$. Patient DCs were characterized by a more mature phenotype compared with controls $(P=0.016)$, and had impaired production of $I \mathrm{~L}-\mathrm{I} 2$ $(P<0.00 \mathrm{I})$. These alterations were reverted by surgical resection of the tumour. To investigate the possible role of some tumourrelated immunoactive soluble factors, we measured the plasmatic levels of vascular endothelial growth factor, IL-I0 and spermine. A significant inverse correlation between spermine concentration and the percentage of DCs expressing IL-I 2 was found. Evidence was also obtained that in vitro exposure of monocyte-derived DCs to spermine promoted their activation and maturation, and impaired their function. Taken together, our results suggest that both the above-described mechanisms could concomitantly act in breast cancer to affect DC differentiation, and that spermine could be a mediator of dysfunctional maturation of DCs.

British Journal of Cancer (2003) 89, 1463- |472. doi:I0.1038/sj.bjc.660I243 www.bjcancer.com

(c) 2003 Cancer Research UK
\end{abstract}

Keywords: tumour immunity; dendritic cells; cell surface molecules; cytokines

Dentritic cells (DCs) represent the most potent professional antigen-presenting cells, because of their widespread localisation in all sites of antigen entry, their ability to process tumour antigens and present them on HLA class II as well as class I molecules, their high expression of costimulatory molecules, and their production of regulatory cytokines (Rescigno et al, 1999; Larsson et al, 2001). Owing to the unique ability of $\mathrm{DCs}$ to stimulate naive $\mathrm{T}$ lymphocytes and therefore to initiate tumour-specific cytotoxic immune responses (Croft et al, 1992), these cells are critical elements of antitumour immunity induction.

Tumours have at least two mechanisms by which they can alter DC maturation and function. The first one affects the ability of haematopoietic progenitor cells to differentiate into functional DCs during the early stages of their maturation. In vitro, it has been demonstrated that factors that can be produced by tumour cells, including vascular endothelial growth factor (VEGF), M-CSF and IL-6, inhibit DC maturation from CD34 + cells (Gabrilovich et al, 1996; Menetrier-Caux et al, 1998). In vivo, tumour-derived VEGF has been proposed as the most likely factor to affect the early stage of DC maturation in the bone marrow (Ishida et al, 1998; Gabrilovich et al, 1999). In breast, head and neck and lung cancer, the inhibitory effects of VEGF on DC differentiation have been described to cause a decrease of PB DCs closely associated

*Correspondence: Dr S Della Bella; E-mail: silvia.dellabella@unimi.it Received 17 March 2003; revised 7 July 2003; accepted 8 July 2003 with accumulation of immature myeloid cells lacking markers of mature haematopoietic cells (Almand et al, 2000). The second mechanism by which tumours can alter DC maturation affects their differentiation from $\mathrm{CD} 14+$ monocyte precursors. This pathway, that is also mediated by soluble tumour-derived factors, acts by promoting an early but dysfunctional maturation of DCs. In particular, it has been demonstrated in vitro that the addition of tumour supernatants during DC differentiation from PB monocytes induces the generation of DCs that are more mature and that display a diminished capacity to take up antigens and to produce regulatory cytokines, and do not develop full allostimulatory activity (Kiertscher et al, 2000).

Whereas several tumour-derived soluble factors are known to affect DC differentiation from CD34+ cells (Gabrilovich et al, 1996; Menetrier-Caux et al, 1998), the mediators leading to the premature phenotypic maturation of monocyte-derived DCs still remain to be determined. A number of tumour-derived factors with the capacity of altering the maturation of $\mathrm{CD} 34+$ or $\mathrm{CD} 14+$ precursors, including VEGF, TGF- $\beta$, IL-10 and $\mathrm{PGE}_{2}$, have been excluded to be implicated in this pathway (Kiertscher et al, 2000). Polyamines are potential candidates, because they are important modulators of immune functions and occur at high concentrations in actively proliferating tissues (Seiler and Atanassov, 1994; Zhang et al, 1997). Spermine, in particular, has been suggested to contribute to the decreased immune reaction against tumours. In fact, elevated levels of spermine have been reported in the plasma and urine of patients with tumours, including breast 
cancer (Chaisiri et al, 1979; Lee et al, 1998). Furthermore, spermine has recently been demonstrated to inhibit the production of IL-12 by in vitro-stimulated macrophages (Haskò et al, 2000).

The aim of the present study was to evaluate the in vivo relevance of the above-described pathways followed by tumours to alter DC maturation and function. For this purpose, we enumerated and functionally characterised DCs in the peripheral blood of patients with breast cancer. To avoid isolation or culture procedures for the enrichment of DCs that may induce the selection of particular cell subsets and/or phenotypic and functional modifications of DCs present in the sample, our analyses were directly performed by flow cytometry on wholeblood samples. Our results confirmed that the number of DCs is decreased in the peripheral blood of cancer patients. In particular, the myeloid CD11c + subpopulation of DCs was dramatically reduced. Furthermore, DCs from cancer patients were characterised by a more mature immunophenotype compared with controls, and had impaired production of IL-12. Therefore, they appeared affected by a dysfunctional maturation similar to that induced in vitro by tumour supernatants during DC maturation from monocyte precursors (Kiertscher et al, 2000). These alterations in the maturation of DCs were completely reverted by surgical resection of the tumour. In vitro evidence provided in this study suggests that spermine could be a possible mediator by which breast cancer affects DC functions.

\section{MATERIALS AND METHODS}

\section{Patient selection}

In all, 53 patients aged $29-86$ (mean 58 ) years with histologically confirmed invasive breast cancer were enrolled into the study. Peripheral venous heparinised blood samples were obtained from all patients before any surgical, chemotherapic and/or radiant treatment. Staging was performed in accordance with the American Joint Committee on Cancer criteria (Sobin and Witterkind, 2002). A total of 15 patients had stage I disease, 16 had stage IIA and 22 had stage IIB. In all 68, sex- and age-matched healthy donors (range 24-88, mean 55 years) were used as controls. Six age-matched patients with benign tumour of the breast and six with in situ breast carcinoma were also included. Informed consent was obtained from all individuals.

\section{Immunophenotypic analysis and counting of peripheral blood cells}

Whole peripheral blood samples $\left(1 \times 10^{6}\right.$ cells in $100 \mu$ test $\left.^{-1}\right)$ were analysed by direct immunofluorescence using three-colour stainings with mAbs directly conjugated with fluorochromes FITC, PE and PerCP. Erythrocytes were lysed after staining, using FACS Lysing Solution (Becton Dickinson, San Jose, CA, USA) according to the manufacturer's instructions. DCs were identified as positive for anti-HLA-DR PerCP (Becton Dickinson) and negative for a mixture of FITC-conjugated mAbs (Caltag Laboratoires, Burlingame, CA, USA) specific for lineage markers on T cells (CD3), B cells (CD19, CD20), NK cells (CD16) and monocytes (CD14). AntiCD11c PE (Caltag Laboratoires) or anti-IL3R $\alpha$ (CD123) PE (Pharmingen, San Diego, CA, USA) were used for identification of myeloid and plasmacytoid DC subpopulations, respectively. Cells labelled with isotype control mAbs were included to determine background fluorescence. All operations were done at $4{ }^{\circ} \mathrm{C}$. Three-colour analysis was performed using a FACScan flow cytometer (Becton Dickinson) using CellQuest software (Macintosh). Since PB DCs are characterised by forward scatter (FSc) similar to monocytes and side scatter (SSc) similar to lymphocytes (Upham et al, 2000), an acquisition gate was established based on FSc and SSc, which included both the lymphocyte and monocyte populations (mononuclear cells), but excluded most granulocytes and debris. Owing to the low frequency of lineage-/HLA-DR + cells, we routinely collected 50000 events to visualise and gate on this population more easily. Conventional haematological parameters in comparable blood samples were also measured using an ADVIA 120 automated haematology analyser (Bayer Diagnostics, Basingstoke, Berkshire, UK). Estimates of the absolute numbers of DCs in blood were calculated from the proportion of DCs recorded in the mononuclear gate determined by flow cytometry multiplied by absolute mononuclear cell count. The assumption was that lymphocytes and monocytes, as determined by the haematology cell counter, together constitute the mononuclear fraction identified by flow cytometry. PE-conjugated anti-CD80, CD83, CD86 (Pharmingen) and CD119 (Caltag Laboratoires) were used to evaluate the activation and maturation states of Lin-/HLA-DR + DCs, directly in fresh whole-blood samples or in blood samples diluted $\mathrm{vv}^{-1}$ in RPMI 1640 medium (Euroclone, Wetherby, West York, UK), and incubated for $5 \mathrm{~h}$ with or without LPS $\left(100 \mathrm{ng} \mathrm{ml}^{-1}\right.$; from Escherichia coli, serotype 055:B5; Sigma). The frequency of DC precursors in the peripheral blood was determined by direct immunofluorescent staining with FITC-conjugated anti-CD34 or CD14 antibodies (Caltag Laboratoires).

\section{Cytoplasmic cytokine expression}

Expression of the cytokines IL-12 and IL-10 in the cytoplasm of PB Lin-/HLA-DR + DCs was determined by flow cytometry. Whole peripheral blood $(500 \mu \mathrm{l})$ supplemented with $500 \mu \mathrm{l}$ of RPMI 1640 medium was incubated for $5 \mathrm{~h}$ with or without $100 \mathrm{ng} \mathrm{ml}^{-1}$ LPS. The protein transport inhibitor brefeldin A (BFA) $\left(10 \mu \mathrm{g} \mathrm{ml}^{-1}\right.$; Sigma, St Louis, MO, USA) was added during the last $4 \mathrm{~h}$, to allow intracellular accumulation of cytokines. Incubation was performed at $37^{\circ} \mathrm{C}$ in a $5 \% \mathrm{CO}_{2}$ humid atmosphere in a sterile environment. Doses of BFA and LPS, and incubation times, were optimised in preliminary experiments. At the end of the incubation period, samples were aliquoted and labelled with appropriate combinations of mAbs for staining of surface markers. Cells were then fixed, permeabilised and stained with cytokine-directed mAbs anti-IL-12 PE and anti-IL-10 PE (Caltag Laboratoires), using the Fix \& Perm reagent (Caltag Laboratoires) (Almeida et al, 1999; Bueno et al, 2001). Cytokine-directed mAbs were used at saturating concentrations and conditions. Samples stimulated under the same culture conditions in the absence of BFA showed undetectable cytokine levels. Cells labelled with isotype control mAbs were included to determine background fluorescence. The evaluation of cytokine production was based on the percentage of cytokine expressing cells. Cytokine production by T lymphocytes was also determined by flow cytometry, as percentages of cells expressing cytokines upon stimulation with PMA plus ionomycin (Sigma Chemical, St Louis, MO, USA) (Rostaing et al, 1999). To avoid ionophore-induced release of prostaglandins and thromboxane by platelets (Knapp et al, 1977) present in whole-blood samples, cultures of PBMCs were performed. Briefly, PBMCs were isolated from heparinised venous blood by density centrifugation on lympholyte (Cedarlane Labs, Hornby, Canada), as previously described (Della Bella et al, 2001). The cells were suspended at a concentration of $1 \times 10^{6} \mathrm{cells} \mathrm{ml}^{-1}$ in complete culture medium consisting of RPMI 1640 supplemented with $10 \%$ heat-inactivated $\mathrm{AB}$ human serum, $2 \mathrm{~mm}$ glutamine, $50 \mathrm{U} \mathrm{ml}^{-1}$ penicillin, $50 \mu \mathrm{g} \mathrm{ml}^{-1}$ streptomycin, in the presence of $10 \mu \mathrm{g} \mathrm{ml}^{-1} \mathrm{BFA}$ and in the presence or absence of $25 \mathrm{ng} \mathrm{ml}^{-1}$ PMA and $1 \mu \mathrm{g} \mathrm{ml}^{-1}$ ionomycin. Cultures were incubated for $18 \mathrm{~h}$ at $37^{\circ} \mathrm{C}$ in a $5 \% \mathrm{CO}_{2}$ humid atmosphere in a sterile environment. Doses of PMA and ionomycin and incubation time were optimised in preliminary experiments. After incubation, the cells were processed for flow cytometric analysis as described above. The percentage of $\mathrm{T}$ lymphocytes, identified based on the surface expression of CD3, 
expressing type 1 cytokines IL- 2 and IFN- $\gamma$, and type 2 cytokine IL4 , was evaluated.

\section{Measurement of plasma levels of VEGF, IL-10 and spermine}

Patient and control plasma samples were obtained by centrifugation of heparinised peripheral blood, and stored at $-20^{\circ} \mathrm{C}$. A commercial ELISA kit was used to measure plasmatic concentrations of VEGF (R\&D Systems, Minneapolis, MN, USA), according to the manufacturer's instructions. The IL-10 ELISA was performed using IL-10-specific mAb 9D7 and biotinylated 12G8 (Endogen, Woburn, MA, USA). Plasmatic spermine concentrations were determined by reversed-phase high-performance liquid chromatography after derivatisation with dansyl chloride, as described (Marchesini et al, 1992).

\section{Effects of spermine on in vitro cultured DCs}

Monocyte-derived DCs were generated from the adherent fraction of PBMCs obtained from healthy control subjects, as described (Bender et al, 1996). Briefly, PBMCs were allowed to adhere for $2 \mathrm{~h}$ in culture flasks, nonadherent cells were gently removed, and the remaining cells were cultured in RPMI 1640 containing 10\% heatinactivated FCS (Euroclone, Wetherby, West York, UK) and supplemented with $800 \mathrm{U} \mathrm{ml}^{-1}$ GM-CSF (Novartis, Italy) and $10 \mathrm{ng} \mathrm{ml}^{-1}$ IL-4 (PeproTech, London, UK). Cultures were fed every other day with fresh medium and cytokines. The effects of spermine on DC differentiation were examined by adding spermine (Sigma-Aldrich, St Louis, MO, USA) at the initiation of culture in parallel cultures. Aminoguanidine was added to cells along with spermine to inhibit the action of polyamine oxidase. Concentrations of spermine ranging from 0.5 to $4 \mu \mathrm{M}$ were used, because these levels were reported to have immunomodulatory effects (Haskò et al, 2000), and were relevant to plasmatic ranges occurring in our patients. Dendritic cells were collected at day 5 . The immunophenotype of DCs was analysed by three-colour FACS analysis with 5000-10000 events acquired for each sample. Endocytosis was assessed by the uptake of FITC-dextran (Sallusto et al, 1995). Dendritic cells were incubated for $1 \mathrm{~h}$ at $37^{\circ} \mathrm{C}$ in the presence of $1 \mathrm{mg} \mathrm{ml}^{-1}$ FITC-dextran (70000 m.w.; Molecular Probes, Eugene, OR, USA). Control cells were incubated on ice for $1 \mathrm{~h}$. After extensive washing, the cells were analysed by singlecolour FACS analysis. Results were expressed as the difference between mean fluorescence intensity (MFI) obtained at 37 and $0{ }^{\circ} \mathrm{C}$ (negative control). Phagocytosis of apoptotic cells by DCs was analysed by flow cytometry as reported by Bellone et al (1997) with some modifications. Briefly, allogeneic monocyte-depleted PBMCs were labelled with $0.5 \mu \mathrm{M}$ chloro-methyl-fluorescein-diacetate (CMFDA; Molecular Probes) for $30 \mathrm{~min}$ at $37^{\circ} \mathrm{C}$, washed extensively and incubated for $24 \mathrm{~h}$ in medium supplemented with $10 \mu \mathrm{M}$ $\mathrm{H}_{2} \mathrm{O}_{2}$ to induce apoptosis. Chloro-methyl-fluorescein-diacetatelabelled apoptotic cells were then incubated with DCs at a ratio of $1: 1$ at $37^{\circ} \mathrm{C}$. After $2 \mathrm{~h}$, cells were washed and treated with $0.05 \%$ trypsine $/ 0.02 \%$ EDTA for $3 \mathrm{~min}$ to disrupt cell - cell binding. Phagocytosis was quantified by flow cytometry as the percentage of CMFDA + DCs. To evaluate their allostimulatory capacity, DCs were cocultured for 5 days with allogeneic monocyte-depleted PBMCs, at a ratio of $1: 20$. During the last $6 \mathrm{~h}$ of culture, $20 \mu \mathrm{M} 5$ bromo-2'-deoxyuridine (BrdU; Sigma Chemical Company, St Louis, MO, USA) was added, and the proliferation of allogeneic $\mathrm{T}$ lymphocytes was evaluated by flow cytometry as BrdU incorporation by $\mathrm{CD} 3+$ cells, as described by Toba et al. Data are expressed as the percentage of proliferating $\mathrm{BrdU}+\mathrm{T}$ lymphocytes. IL-12 production was assessed by stimulating monocyte-derived DCs for $24 \mathrm{~h}$ with soluble recombinant CD40L $\left(1 \mu \mathrm{g} \mathrm{ml}^{-1}\right.$; Alexis Biochemicals, San Diego, CA, USA). The IL-12 p70 ELISA was performed using p70-specific mAb $20 \mathrm{C} 2$ and biotinylated C8.6 (Endogen).

\section{Statistical analysis}

Comparisons of samples to establish the statistical significance of difference were determined by the two-tailed Student's $t$-test for independent samples. The paired $t$-test and the linear regression analysis were also used when indicated. Results were considered to be statistically significant when $P$ was $\leqslant 0.05$.

\section{RESULTS}

\section{Quantitation of PB DCs and DC precursors}

The percentage of DCs, identified as Lin-/HLA-DR + cells, in the mononuclear cell population was significantly lower in the peripheral blood of breast cancer patients compared with healthy controls (breast cancer: $0.87 \pm 0.04 \% \quad$ (mean \pm s.e.m.) of the mononuclear cells vs controls: $1.45 \pm 0.06 \%$; $P<0.001)$. The number of DCs in the blood, estimated by using the percentages generated by FACS analysis and the absolute mononuclear cell count, was also significantly lower in cancer patients than in controls $\quad\left(19.37 \pm 1.10 \times 10^{3} \mathrm{ml}^{-1}\right.$ vs $\left.27.71 \pm 1.59, \quad P<0.001\right)$ (Figure 1). Within the Lin-/HLA-DR + cells, the percentage of CD11c + DCs tended to be lower in cancer patients $(49.7 \pm 2.1 \mathrm{vs}$ $54.6 \pm 2.2 \%, P=$ n.s.) and that of CD123 + DCs tended to be higher $(32.1 \pm 1.8$ vs $27.5 \pm 1.8 \%, P=$ n.s.). This resulted in a significant decrease of PB myeloid Lin-/HLA-DR +/CD11c + DCs in breast cancer patients compared with control subjects $\left(9.61 \pm 0.68 \times 10^{3} \mathrm{ml}^{-1}\right.$ vs $\left.14.80 \pm 0.95, P<0.001\right)$, while the number of PB plasmacytoid Lin-/HLA-DR + /CD123 + DCs was unaffected. There was no correlation between DC number and tumour size or stage in patients with invasive breast cancer. The decrease in the number of DCs in the blood was already apparent, although not significant, in the few patients with carcinoma in situ included in the study $\left(20.17 \pm 2.92 \times 10^{3} \mathrm{ml}^{-1}\right)$, while DC number was un-

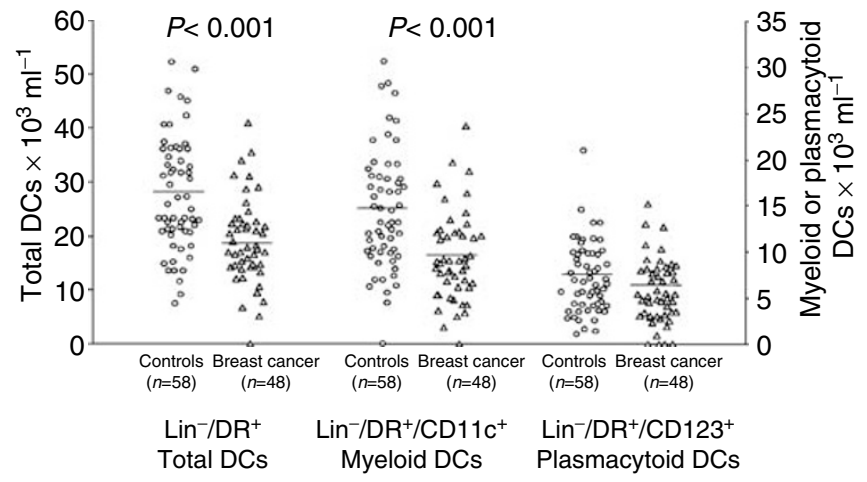

Figure I Absolute number of PB DCs in breast cancer patients compared with controls. A significant decrease in PB Lin-/HLA-DR + cells (left axis) and myeloid DCs (right axis) was observed in cancer patients. Whole blood was stained with a cocktail of FITC-conjugated mAbs recognising $\mathrm{CD} 3, \mathrm{CD} / 4, \mathrm{CD} / 6, \mathrm{CD} / 9$ and $\mathrm{CD} 20$, and with PerCPconjugated anti-HLA-DR mAb; myeloid DCs were identified as lineage-/ HLA-DR + /CDIIc + cells, plasmacytoid DCs (right axis) as lineage-/HLA$\mathrm{DR}+/ \mathrm{CDI} 23+$ cells. Absolute DC counts were then determined indirectly by multiplying the percentage of DCs in the mononuclear gate times the sum of the lymphocyte and monocyte determined on a differential blood cell counter. Each symbol represents a single sample. Open circles: control subjects; open triangles: breast cancer patients. Mean values represented by horizontal lines in each series. $P$-values were determined using the t-test for independent samples, patients compared with controls. 
affected in the patients with benign breast tumours $(26.66 \pm$ $5.37 \times 10^{3} \mathrm{ml}^{-1}$ ). The frequency of CD34 + cells in the blood of cancer patients was significantly higher than in control subjects $(1.13 \pm 0.32 \%, n=7$ vs $0.57 \pm 0.06, n=12 ; P=0.041)$. Finally, the frequency of CD14 + monocyte precursors did not differ between patients and controls $(5.89 \pm 2.02, n=38$, and $6.06 \pm 0.02, n=14$, respectively).

\section{Immunophenotype of PB DCs}

The activation state of $\mathrm{PB}$ DCs, assessed as the expression of the costimulatory molecules CD80 and CD86 on Lin-/HLA-DR + cells, did not significantly differ between patients and controls, although cancer patients presented a slightly higher percentage of CD80 + DCs $(9.15 \pm 1.88 \%$ of the DCs vs $6.69 \pm 0.94 \%)$ (Figure $2 \mathrm{~A}$ ). Otherwise, analysis of the maturation state of Lin-/HLA-DR + DCs, evaluated as the expression of CD83 molecule, showed that breast cancer patients had a significantly higher percentage of mature CD83 + DCs compared with control subjects $(5.23 \pm 0.57$ vs $3.00 \pm 0.75 \% ; P=0.019)$. As shown in Figure $2 \mathrm{~B}, \mathrm{DC}$ maturation appeared correlated to the clinical stage of disease, since the

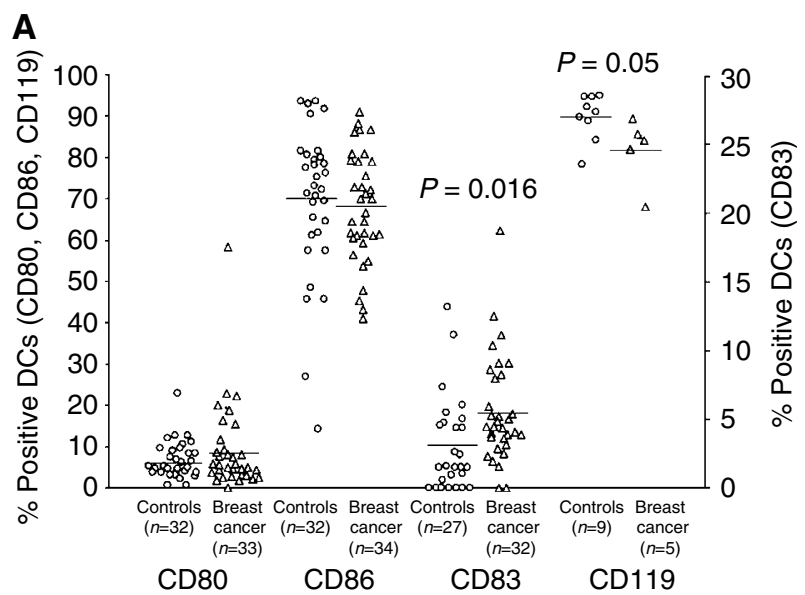

B

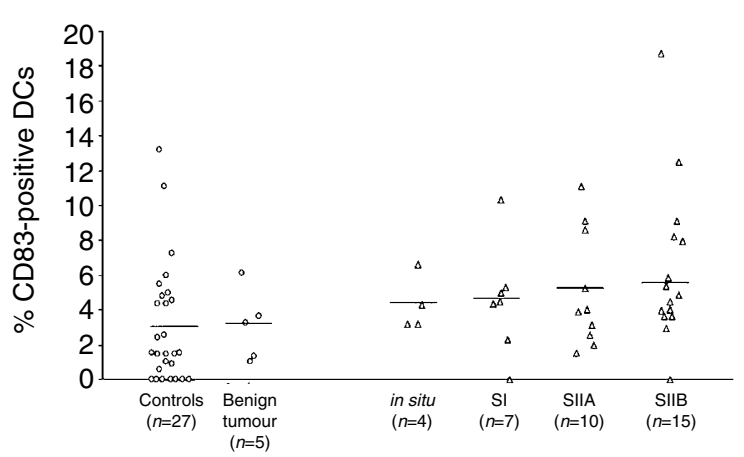

Figure 2 Immunophenotype of PB DCs. (A) The activation state of Lin-/ HLA-DR + DCs, assessed as the expression of the costimulatory molecules CD80 and CD86 (left axis), was similar in patients and controls, while the frequency of mature DCs was significantly higher in breast cancer individuals, as assessed by higher percentages of Lin-/HLA-DR + cells expressing CD83 (right axis) and lower percentages of Lin-/HLA-DR + cells expressing CDII9 (left axis). (B) The percentage of mature DCs, identified as Lin-/HLA-DR + cells expressing the CD83 maturation marker, increased progressively with the severity of breast cancer. Each symbo represents a single sample. Open circles: control subjects; open triangles: breast cancer patients. Mean values are represented by horizontal lines in each series. $P$-values were determined using the $t$-test for independent samples, patients compared with controls. percentage of $\mathrm{CD} 83+$ DCs tended to increase progressively with the severity of breast cancer (carcinoma in situ: $4.31 \pm 0.81$; stage I: $4.91 \pm 2.00$; stage IIA: $5.11 \pm 1.05$; stage IIB: $5.46 \pm 0.83)$. The percentage of CD83 + DCs in patients with benign tumours of the breast was absolutely unaffected $(3.07 \pm 0.92)$ as compared with controls. To evaluate the early-maturation stage of DCs, in a few cases we also analysed DC surface expression of the IFN- $\gamma$ receptor (CD119), which is progressively down-regulated on maturing DCs (Kalinski et al, 1999). Breast cancer patients indeed had a significant lower percentage of CD119+ Lin-/HLA-DR + DCs compared with healthy controls $(82.00 \pm 3.63$ of the DCs $v s 89.92$ $\pm 1.85 \% ; P=0.05)$.

\section{Effects of LPS stimulation on activation and maturation of DCs}

To assess the ability of PB DCs from breast cancer patients to be activated following stimulation, we exposed whole-blood samples to LPS for $5 \mathrm{~h}$, and subsequently analysed the expression of costimulatory molecules and CD83 on DCs. In both patients and controls, this short-period incubation with LPS induced a statistically significant increase in the percentage of both CD80 + Lin-/HLA-DR + DCs and CD83 + Lin-/HLA-DR + DCs (patients and controls: paired $t$-test $P<0.001$ ). LPS also induced an overexpression of CD86 above the constitutive levels in both the groups, measured as MFI (patients and controls: paired $t$-test $P<0.001)$. The activation and maturation response of DCs to LPS did not differ between patients and controls, with similar percentages of CD $80+$ DCs (patients: $48.43 \pm 4.78 \%$ of DCs vs controls: $41.17 \pm 2.90 \%)$ and CD83 + DCs (75.94 \pm 3.17 vs 71.21 $\pm 2.61 \%$ ), and a similar DC expression of CD86 (MFI: $398.36 \pm$ 39.15 vs $349.67 \pm 27.45 \%$ ) observed in both the groups in LPSexposed blood samples. Incubation of whole-blood samples in plastic tubes in the presence of culture medium without LPS induced a slight activation and maturation of DCs, which emphasised differences between patients and controls, resulting in significantly higher percentages of CD80 + DCs $(9.80 \pm 1.72 v s$ $3.86 \pm 0.77 \%, P=0.004)$ and CD83 + DCs $(14.86 \pm 3.51$ vs 4.53 $\pm 1.42 \%, P=0.011)$, and higher DC expression of CD86 (163.14 \pm 20.33 vs $86.47 \pm 10.11 \%, P=0.028$ ) in breast cancer patients than in control subjects.

\section{Cytoplasmic cytokine expression in PB DCs}

Owing to the central role played by regulatory cytokines produced by DCs in directing immune responses, we further asked whether the ability of PB DCs from breast cancer patients to produce cytokines was impaired. We incubated whole-blood samples with or without LPS in the presence of BFA for $5 \mathrm{~h}$, and subsequently analysed the expression of intracellular cytokines in unseparated Lin-/HLA-DR + DCs. In both the groups, incubation of peripheral blood samples with LPS induced a significant increase in the percentage of DCs expressing either IL-12 or IL-10 (patients and controls: paired $t$-test $P<0.001$ ). As shown in Figure 3, while the unstimulated expression of IL-12 was similar in the two groups, the percentage of DCs expressing IL-12 upon LPS stimulation was significantly lower in breast cancer patients than in healthy controls $(23.75 \pm 1.35$ vs $34.28 \pm 1.38 \%, P<0.001)$. A representative flow cytometric analysis is presented in Figure 4. The reduction in IL-12 expression in cancer patients was also evident when we compared the mean fluorescence intensity for IL-12 staining in patients and controls (60.9 \pm 5.6 vs $86.4 \pm 11.2 \%, \quad P=0.036)$. The percentage of DCs expressing cytoplasmic IL-10 was significantly higher in cancer patients in unstimulated conditions $(3.70 \pm 0.35$ vs $2.65 \pm 0.22 \%, P=0.046)$, while it was similar to control subjects upon LPS stimulation. As for the DC count, the decrease of DCs expressing IL-12 following LPS stimulation 


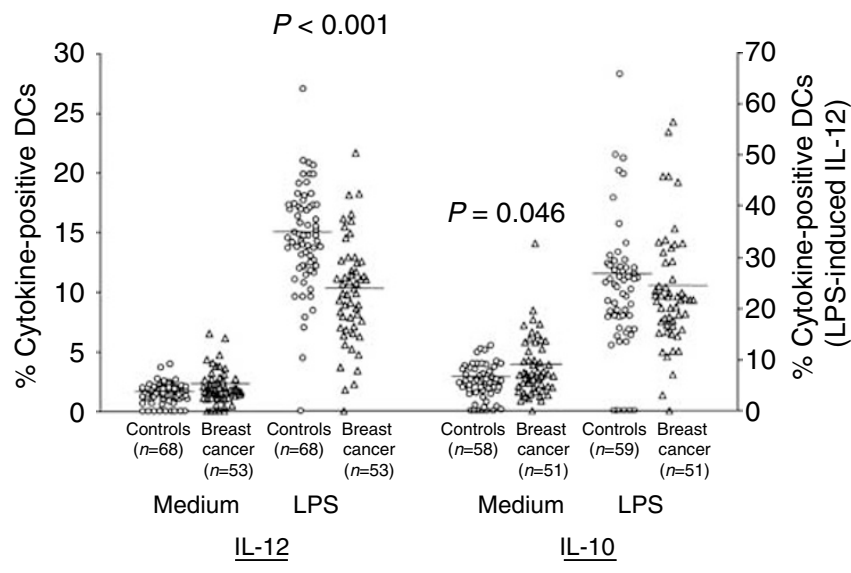

Figure 3 Cytokine production by peripheral blood DCs in breast cancer patients compared with control subjects. A significantly lower percentage of PB DCs producing IL- 12 upon LPS stimulation was observed in cancer patients. After incubation for $5 \mathrm{~h}$ in the presence or absence of LPS with BFA added during the last $4 \mathrm{~h}$, whole-blood samples were stained with a cocktail of FITC-conjugated mAbs recognising CD3, CDI4, CD I6, CDI9 and CD20, and with PerCP-conjugated anti-HLA-DR mAb. Intracellular accumulation of cytokines within DCs, identified as lineage-/HLA-DR + cells, was evaluated after staining with $\mathrm{PE}$-conjugated $\mathrm{mAbs}$ directed against either IL-I 2 or IL- I0. Each symbol represents a single sample. Open circles: control subjects; open triangles: breast cancer patients. LPS-induced IL-12 values referred to the right axis; all the other values to the left axis. Mean values represented by horizontal lines in each series. $P$-values were determined using the t-test for independent samples, patients compared with controls.

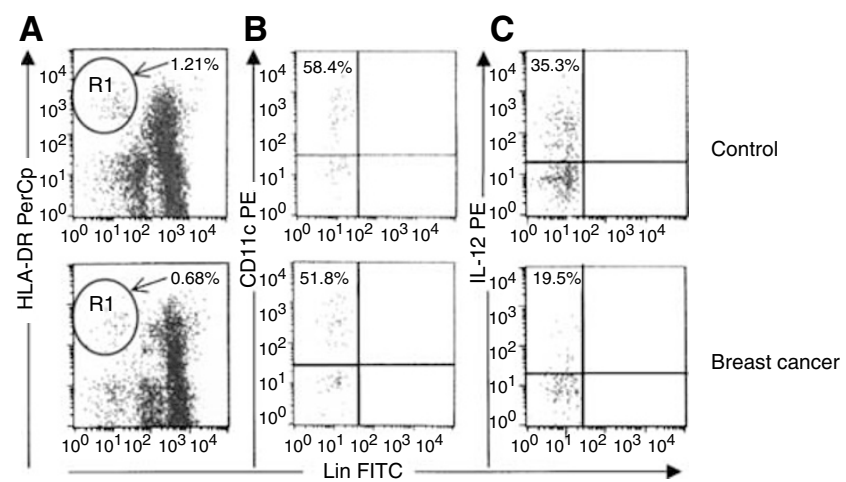

Figure 4 Identification and characterisation of PB DCs in whole peripheral blood samples. Comparison between representative flow cytometric analyses from a control subject (upper line) and a breast cancer patient (lower line). (A) Gated on a mononuclear cell analysis region, DCs were identified on the basis of their lack of labelling for the lineage markers CD3, CD I4, CD I6, CDI9 and CD20, but positive staining for HLA-DR (RI). (B) Gated on RI events, myeloid DCs were identified for their surface expression of CDI Ic. (C) Gated on RI events, PB DCs producing IL-12 upon LPS stimulation were identified for their intracellular accumulation of the cytokine.

was not observed in patients with benign tumour of the breast (39.24 \pm 10.12$)$, and was only slight in patients with carcinoma in situ (32.28 \pm 3.39). A significant positive correlation was observed between the percentage of DCs expressing IL-12 and the percentage of DCs expressing CD119 on their surface $(r=0.543, n=13, P=0.05)$. No significant correlation was found between cytokine expression by DCs and size or stage of the tumour, or between the percentages of DCs expressing IL-12 and IL-10.

\section{Cytoplasmic cytokine expression in T lymphocytes}

To assess whether the ability of $\mathrm{T}$ lymphocytes from breast cancer patients to produce cytokines was also affected, we stimulated PBMCs with PMA and ionomycin in the presence of BFA, and analysed the intracellular expression of type 1 and type 2 cytokines by $\mathrm{CD} 3+$ lymphocytes. In both the groups, incubation of PBMCs with PMA and ionomycin induced a significant increase in the percentage of $\mathrm{T}$ lymphocytes expressing either IL-4 (patients: paired $t$-test $P=0.003$; controls: $P<0.001)$ or IL-2 (patients and controls: $P<0.001$ ) or IFN- $\gamma$ (patients and controls: $P<0.001)$. As shown in Figure $5 \mathrm{~A}$, the percentages of $T$ lymphocytes expressing cytokines in unstimulated cultures were low and similar in patients and controls. Upon PMA stimulation, the percentage of T lymphocytes expressing IL-4 was significantly higher in breast cancer patients than in controls $(2.36 \pm 0.49 v \mathrm{~s}$ $1.37 \pm 0.16 \%, P=0.039$ ), while the percentages of $\mathrm{CD} 3+$ cells expressing either IL-2 or IFN- $\gamma$ were slightly decreased in cancer patients. Since the balance between type 1 and type 2 cytokines is thought to be more relevant than absolute values of single cytokines in driving immune responses, the ratios between cytokine-expressing lymphocytes were also considered. As shown in Figure 5B, both the ratio between IL- $2+$ and IL-4+ lymphocytes and the ratio between IFN- $\gamma+$ and IL- $4+$ lymphocytes, in PMA-stimulated cultures, were significantly lower in breast cancer than in control subjects (IL-2/IL-4: $10.06 \pm 1.61$ vs $25.01 \pm 5.97 \%, P=0.049$; IFN- $\gamma /$ IL-4: $10.43 \pm 1.47$ vs $21.07 \pm$ $4.18 \%, P=0.048)$. No correlation was observed between cytokine expression by $\mathrm{T}$ lymphocytes and $\mathrm{DC}$ number or cytokine expression by DCs.

\section{Effects of surgical removal of the tumour on PB DCs}

To assess the impact of surgical resection of the tumour, we compared PB DCs in seven breast cancer patients before and 4 weeks after the surgery, but prior to adjuvant chemotherapy or radiation therapy. As shown in Figure 6, removal of the tumour resulted in normalisation of both the percentage of CD83 + DCs (pre: $6.06 \pm 1.08 \%$; post: $3.21 \pm 0.78 \%$; paired $t$-test: $P=0.001$ ) and the percentage of DCs expressing IL-12 upon LPS stimulation (pre: $21.18 \pm 3.11 \%$; post: $30.07 \pm 0.33 \% ; P=0.042$ ). Removal of the tumour also induced a decrease, although not significant, of the percentage of CD80 + DCs (pre: $10.52 \pm 3.53 \%$; post: $6.41 \pm$ $1.70 \% ; P=$ n.s.). At the time of blood collection, only a partial nonsignificant increase of both the proportion of DCs (pre: $0.72 \pm$ $0.09 \%$ of the mononuclear cell; post: $0.77 \pm 0.05 \%)$ and the absolute number of myeloid DCs (pre: $9.24 \pm 2.17 \times 10^{3} / \mathrm{ml}$; post: $11.13 \pm 1.72$ ) was observed.

\section{Correlation between PB DC functions and plasmatic levels of tumour-derived mediators}

To evaluate whether alterations in PB DCs could depend on tumour-related soluble factors, we analysed the levels of VEGF, IL10 and spermine in the plasma of nine patients compared with an equal number of control subjects. The plasmatic levels of VEGF (breast cancer: range $31.2-177.9 \mathrm{pg} \mathrm{ml}^{-1}$; controls: $43.7-59.6$ ), IL-10 (breast cancer: 20.9 - 31.1; controls: 16.9 - 21.7) and spermine (breast cancer: 0.25 - 4.05; controls: $0.66-2.51$ ) did not significantly differ between groups. However, a significant negative correlation was found between the plasmatic concentration of spermine and the percentage of DCs expressing IL-12 upon stimulation ( $r=-0.768, n=9, P=0.016)$. Furthermore, the levels of spermine tended to be directly correlated with the percentage of CD83 + DCs, although this correlation did not reach statistical significance. No correlation was observed between the plasmatic concentration of VEGF or IL-10 and any DC parameter. 


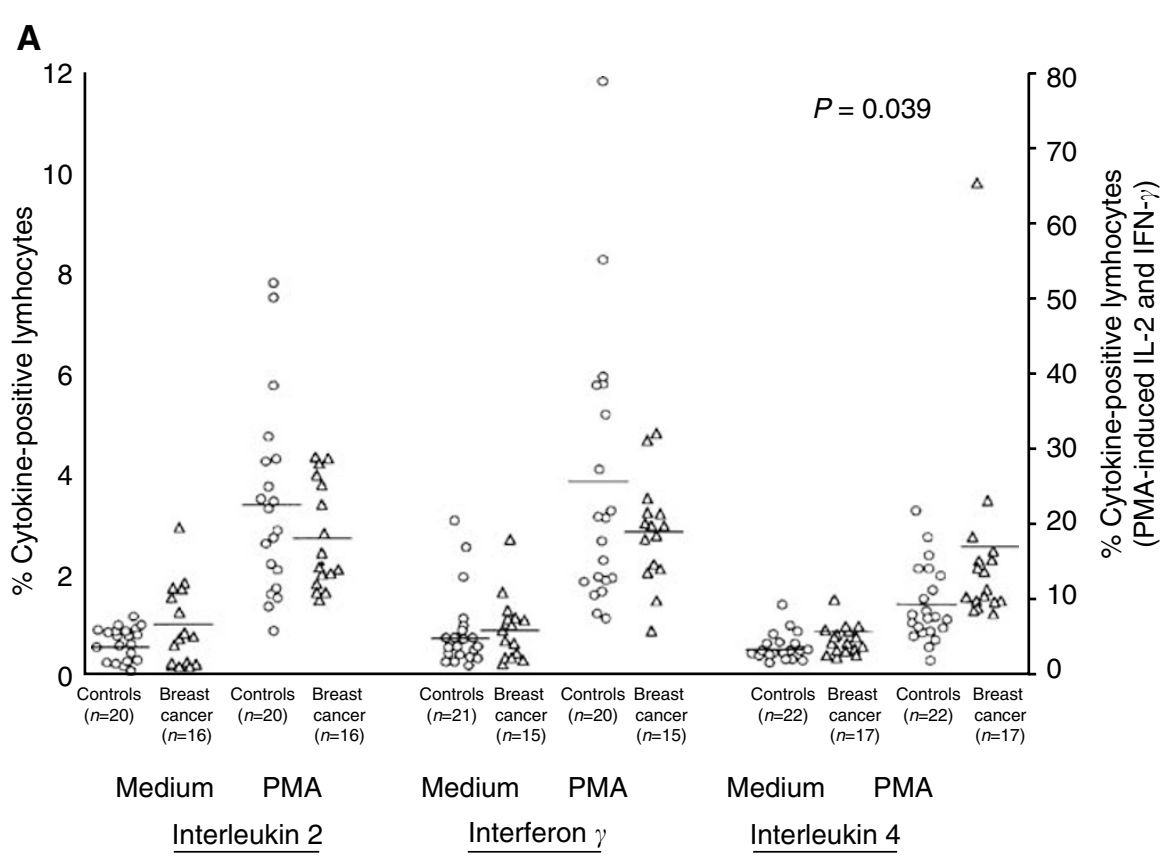

B

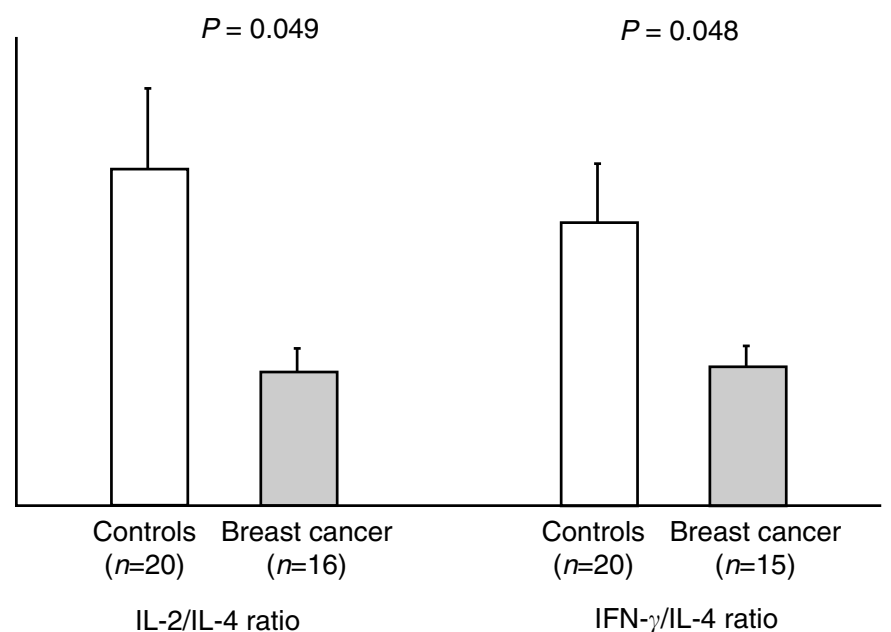

Figure 5 Cytokine production by T lymphocytes in breast cancer patients compared with control subjects. PBMCs were cultured in the presence of BFA with or without PMA plus ionomycin for $18 \mathrm{~h}$. At the end of the cultures, cells were stained with FITC-conjugated anti-CD3 mAb, and intracellular accumulation of cytokines within CD3 + T lymphocytes was evaluated after staining with PE-conjugated mAbs directed against either IL-2 or IFN- $\gamma$ or IL-4. (A) Each symbol represents a single sample. Open circles: control subjects; open triangles: breast cancer patients. Values of PMA-induced IL-2 and IFN- $\gamma$ referred to the right axis, all the others to the left axis. Mean values are represented by horizontal lines in each series. P-values were determined using the $t$ test for independent samples, patients compared with controls. (B) Profile of cytokine production by T lymphocytes, expressed as type I to type 2 cytokine ratios. Both IL-2 to IL-4 and IFN- $\gamma$ to IL-4 ratios were significantly reduced in breast cancer patients compared with controls. Open bars: control subjects; dark bars: breast cancer patients. $P$-values were determined using the $t$-test for independent samples, patients compared with controls.

\section{Effects of spermine on cultured DCs}

To evaluate whether spermine could induce alterations in DC differentiation and function, we cultured monocyte-derived DCs from healthy donors in the presence or absence of spermine. This polyamine did not affect the efficiency of generation of DCs from monocytes, since similar numbers of DCs were obtained in its presence or absence (data not shown). Preliminary results obtained from four independent experiments seem to indicate that exposure of maturing DCs to spermine slightly promotes their maturation, as assessed by a dose-dependent mild increase of DC expression of CD83 - at levels similar to those observed in vivo and of CD40. The results of immunophenotype analysis are reported in Figure 7. As illustrated in the same figure, DCs generated in the presence of spermine showed a reduced capacity to capture antigens, as assessed by a reduced mannose-receptormediated endocytosis (MFI FITC-dextran, mean \pm s.e.m. from $428.9 \pm 81.9$ to $315.7 \pm 86.5 \%)$. The reduced capacity of spermine-conditioned DCs to capture antigens was also measurable as reduced phagocytosis of apoptotic cells (\% CMFDA + DCs: from $18.3 \pm 2.1$ to $11.7 \pm 2.9 \%$ ). Moreover, DCs exposed to spermine exibited a dose-dependent impairment of their allosti- 
A

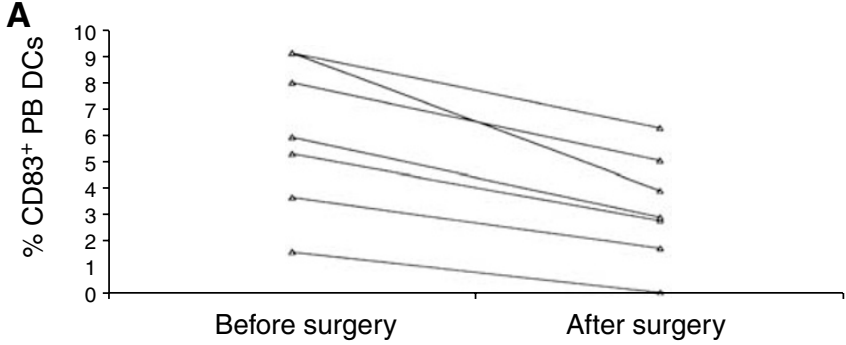

B
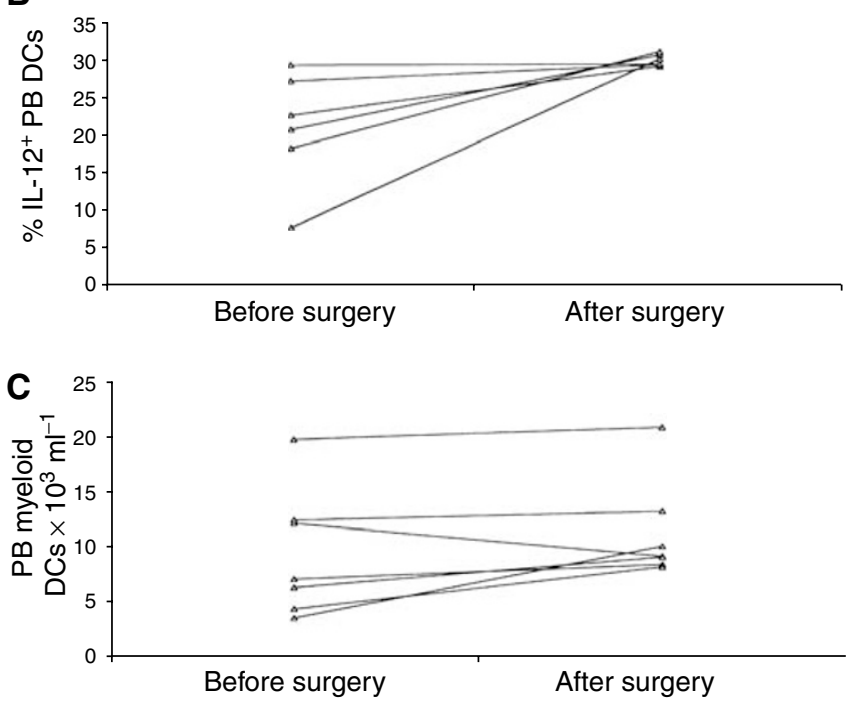

Figure 6 Effects of surgical removal of the tumour on PB DCs. At 4 weeks after surgery, $(\mathbf{A})$ the percentage of CD83 + PB DCs significantly decreased $(P=0.00 \mathrm{I})$, with a reduction of mature PB DCs observed in all the patients; (B) the percentage of PB DCs expressing IL- 12 upon LPS stimulation significantly increased $(P=0.042)$, with a complete normalisation observed in all the patients; $(\mathbf{C})$ the number of myeloid DCs in the peripheral blood of the patients only slightly increased $(P=$ n.s.). Methods as described in Figures $2-4$ Each symbol represents a single sample. $P$ values were determined using the $t$-test for paired samples.

mulatory capacity, as assessed by reduction in the percentage of $\mathrm{BrdU}+$ proliferating allogenic $\mathrm{T}$ lymphocytes on day 5 of culture $(\% \mathrm{BrdU}+\mathrm{CD} 3+$ cells: from $11.4 \pm 2.59$ to $7.7 \pm 2.1 \%)$. A representative experiment is reported in Figure 7. It was possible that the decrease in T-cell stimulatory function seen for DCs cultured with spermine reflected the fact that the T-cell division in these cultures already had peaked, since spermine-conditioned DCs were more mature and may have activated the $\mathrm{T}$ cells more rapidly. This possibility was excluded by a kinetic study, shown in Figure 8. Finally, exposure of maturing DCs to spermine partially inhibited the ability of these cells to produce IL-12 upon stimulation, as detected by ELISA measurement of the cytokine in culture supernatants (from $328 \pm 124$ to $181 \pm 83 \mathrm{pg} \mathrm{ml}^{-1}$ ).

\section{DISCUSSION}

In the present study, we evaluated PB DCs in patients with breast cancer compared with control subjects. We applied flow cytometric methods that allow the enumeration and the immunophenotypical as well as functional characterisation of DCs directly in whole peripheral blood samples (Robinson et al, 1999; Arpinati et al, 2000; Upham et al, 2000). With this method, we observed that Lin-/HLA-DR + DCs are significantly reduced in the peripheral blood of breast cancer patients compared with healthy donors. The reduction was already apparent, although not significant, in patients with in situ breast carcinoma, and was more severe and statistically significant in patients with invasive carcinoma. Within the group of invasive breast cancer, which was composed of patients in the early stage of the disease (I, IIA and IIB), we did not find a correlation between DC count and stage of cancer. The close correlation between DC reduction and cancer was emphasised by the finding that the number of PB DCs was unaffected in the few women who, following surgical removal, were diagnosed as affected by benign breast tumour. A similar reduction of Lin-/ HLA-DR + DCs had been observed by Gabrilovich et al in the peripheral blood of patients with several malignant neoplasias, including a group of subjects with breast cancer at various stages, from I to IV (Almand et al, 2000). Our study confirms and extends these previous observations, focusing on a larger group of earlystage breast cancer patients. Furthermore, Gabrilovich et al estimated blood DC number by extrapolating from the yield of DCs obtained after multistep purification, while we performed DC count directly on whole blood, without any ex vivo enrichment. The results obtained with this procedure, that more directly reflects the in vivo situation, may corroborate the possible role of DC alterations in the clinical evolution of malignancies. Together with the reduction of Lin-/HLA-DR + DCs, we observed a statistically significant increase of $\mathrm{CD} 34+$ cells in the peripheral blood of patients with invasive breast cancer. This increase could be related to tumour-derived factors that may either promote the mobilisation of CD34 + cells from the bone marrow, such as GMCSF (Garrity et al, 1997), or inhibit DC maturation from CD34+ precursors, such as VEGF, M-CSF and IL-6 (Almand et al, 2000). In patients with head and neck squamous cell carcinoma, an increased number of $\mathrm{CD} 34+$ progenitor cells endowed with natural suppressor activity is present in the peripheral blood and within the tumour tissue (Garrity et al, 1997; Lathers et al, 1999). To further investigate the significance of the increase of $\mathrm{PB}$ $\mathrm{CD} 34+$ cells in breast cancer patients, ongoing studies are planned to characterise the immunophenotype and the functional activity of these cells in our patients.

Since human PB DCs can be divided, on the basis of expression of the $\beta$-integrin CD11c (Robinson et al, 1999), into two subpopulations that differ in the origin, expression of phenotypic markers, route of activation and immunological activity, we evaluated their distribution in our patients. We found that the number of myeloid DCs, and not plasmacytoid DCs, was significantly decreased in breast cancer patients compared to controls. This alteration may have a relevant impact on immune defences against cancer. In fact, CD11c + myeloid DCs originate from myeloid bone marrow precursors, express myeloid antigens, and upon stimulation produce high amounts of IL-12, which in turn promotes cell-mediated immune responses that are crucial for the detection and elimination of malignant cells (Cella et al, 1996; Rissoan et al, 1999; Robinson et al, 1999). CD11c- plasmacytoid DCs originate from lymphoid bone marrow precursors, lack myeloid markers, express high levels of the IL-3-receptor- $\alpha$ chain (CD123) and secrete lower amounts of IL-12 (Rissoan et al, 1999; Robinson et al, 1999; Reid et al, 2000; Liu et al, 2001). Although it is now believed that each DC subset has a certain degree of flexibility in directing T-cell responses (Liu et al, 2001; Shortman and Liu, 2002), myeloid DCs still remain higher producers of IL-12 than plasmacytoid DCs and key elements in the induction of cellmediated immune responses.

Since the presence of costimulatory molecules on DC surface is crucial in determining whether engaged $\mathrm{T}$ lymphocytes will become anergic or develop productive immunity (Schultz et al, 1996), we evaluated the expression of CD80 and CD86 on Lin-/ HLA-DR + DCs in our patients, but we did not find significant differences compared with healthy controls. Since another important aspect of DC function is the maturation state, we also 


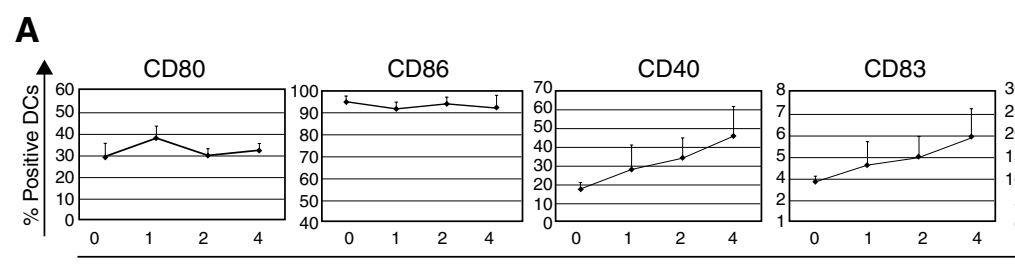

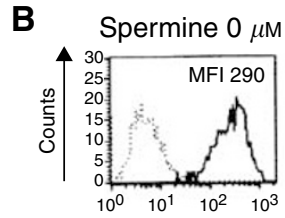

FITC-Dx

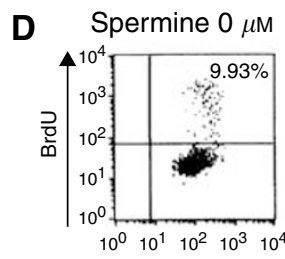

CD3

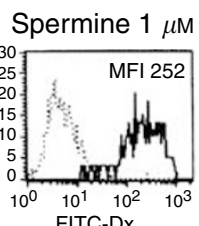

FITC-Dx

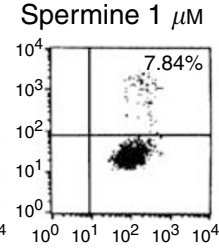

$\mathrm{CD} 3$

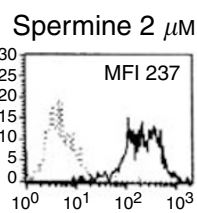

FITC-Dx

Spermine $2 \mu \mathrm{M}$

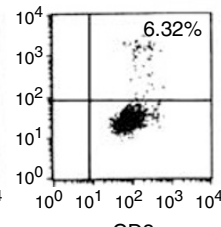

$\mathrm{CD} 3$

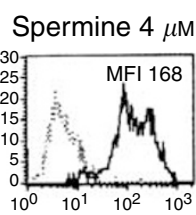

FITC-Dx

Spermine $4 \mu \mathrm{M}$

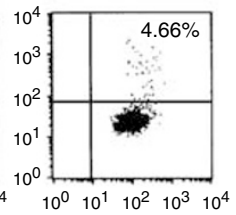

CD3

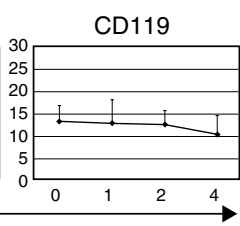

Spermine $\mu \mathrm{M}$

C

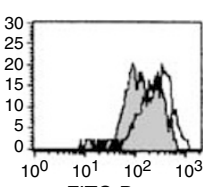

FITC-Dx

E

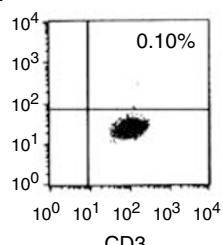

Figure 7 Effects of spermine on in vitro cultured DCs. Monocyte-derived DCs were generated from the adherent fraction of PBMCs obtained from healthy control subjects in the presence of IL-4 and GM-CSF for 5 days. Spermine at the indicated concentrations was added at the initiation of culture and maintained throughout. (A) Exposure of maturing DCs to spermine affected their immunophenotype, promoting a dose-dependent mild increase of DC expression of CD83 and CD40. Data shown are mean \pm s.e.m of four independent experiments. (B) The addition of spermine to maturing DCs impaired their mannose-receptor-mediated FITC-dextran endocytosis, as assessed by a dose-dependent mean fluorescence intensity reduction. Dashed lines indicate FITC-dextran endocytosis at $0^{\circ} \mathrm{C}$ (negative control), and solid lines represent FITC-dextran endocytosis at $37^{\circ} \mathrm{C}$ at the indicated spermine concentrations. This result is representative of four independent experiments. (C) Same experiment as (B). Comparison between FITC-dextran endocytosis by DCs cultured in the absence (white histogram) or presence (grey histogram) of $4 \mu \mathrm{M}$ spermine. (D) Exposure of maturing DCs to spermine affected their allostimulatory capacity. Lymphocyte proliferation was measured by flow cytometry as BrdU incorporation by CD $3+$ cells. The percentages of proliferating allogenic T lymphocytes after coculture for 5 days with DCs generated in the presence of the indicated spermine concentrations are presented. This result is representative of four independent experiments. (E) BrdU incorporation by T lymphocytes cultured for 5 days in the absence of DCs (negative control) is shown.

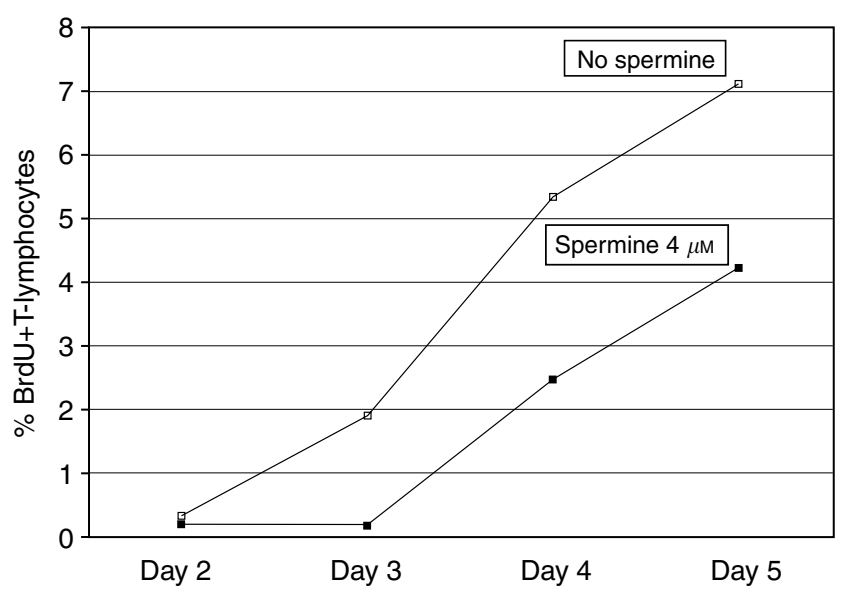

Figure 8 Analysis of T-cell division induced at different days by allogenic unconditioned (white squares) or spermine-conditioned (black squares) DCs. The decrease in T-cell stimulatory function seen for DCs cultured with spermine was not due to a different cell kinetics. Methods as in Figure 7; results expressed as percentages of proliferating allogenic $T$ lymphocytes.

evaluated the expression of the CD83 molecule, a widely used DC maturation marker supposed to be involved in antigen presentation and cellular interactions (Zhou and Tedder, 1995; Lechmann et al, 2002). We observed that the percentage of mature CD83+ DCs is higher in patients with invasive breast cancer compared with subjects of all other groups (in situ carcinoma, benign breast neoplasms and healthy controls). Interestingly, CD83 + DCs have been described in the peritumoral areas of breast cancer samples, while absent in the normal breast tissue (Bell et al, 1999). We are planning further studies to investigate the relationships existing between DCs in peripheral blood and in tumour tissue in our patients. In normal conditions, $\mathrm{PB} \mathrm{CD} 83+\mathrm{DCs}$ are infrequent because DC maturation and CD83 expression follow antigen capture and exposure of DCs to activating stimuli in peripheral tissues. The high percentage of Lin-/HLA-DR + DCs expressing CD83 observed in breast cancer patients could be induced by tumour-derived factors, as suggested by the observation that the increased expression of CD83 by PB DCs was completely reverted in our patients 4 weeks after surgical removal of the tumour. Moreover, in vitro tumour supernatants are able to promote rapid maturation of DCs with upregulation of CD83 molecule expression (Kiertscher et al, 2000). Finally, factors present in the tumour environment in vivo, such as polyamines or prostaglandins, might also interfere with the maturation and/or function of DCs (Haskò et al, 2000; Harizi et al, 2002). In fact, we found that exposure of in vitro maturing DCs to spermine enhanced the expression of CD83, suggesting that this tumour-derived polyamine could be involved in the phenotypic maturation of $\mathrm{PB}$ DCs observed in vivo. Functional impairment of DCs have also been described in haematologic diseases, in particular in chronic and acute myeloid leukaemia, in which defects in antigen processing (Dong et al, 2003) and in allostimulatory activity (Mohty et al, 2001) have been related to the expression by DCs of the same cytogenetic abnormalities expressed by freshly isolated leukaemic cells. It has been suggested that the defects in antigen processing observed 
in chronic myeloid leukaemia DCs may be related to the underlying cytoskeletal changes induced by the expression of the BCR-ABL fusion gene (Dong et al, 2003). At present, we cannot exclude the fact that cytoskeletal alterations may similarly contribute to impaired function of DCs in breast cancer patients.

Owing to the important role of regulatory cytokines of DC origin in the induction and activation of immune responses, we evaluated the cytofluorimetric DC expression of IL-12 and IL-10, both in basal and stimulated conditions. We used LPS as the DC stimulator because LPS, with or without IFN- $\gamma$, has been reported to be the optimal stimulus for analysis of cytokine expression by DCs in whole-blood samples (Almeida et al, 1999; Bueno et al, 2001), and because TLR4, which is required for the response to LPS, is selectively expressed on myeloid CD11c + DCs (Krug et al, 2001). We found that DC constitutive production of IL-10 was increased in patients with invasive cancer, while that of IL-12 was similar to controls. On the contrary, when we evaluated LPS-induced expression of cytokines, we observed an impaired expression of IL-12 by PB DCs from breast cancer patients. The possibility that the reduction in IL-12-producing cells simply reflects the reduction in myeloid DCs seems unlikely because the reduction in the percentage of IL-12-positive DCs largely overcomes the reduction in the percentage of $\mathrm{CD} 11 \mathrm{c}+$ myeloid DCs. Moreover, because the reduction of IL-12 expression in our patients is reversed by tumour excision, we hypothesised that this defect could be directly dependent on cancer mass and on its environmental factors, such as polyamines. This possibility is supported by the inverse correlation existing between plasmatic levels of spermine and the percentage of PB DCs expressing IL-12 in our patients. The ability of spermine to interfere with IL-12 production seems to be confirmed by our preliminary experiments on DCs cultured in vitro in the presence of spermine at concentrations readily achieved in vivo. The impairment of IL-12 production could also be correlated with the increased maturation state of cancer DCs. In fact, it is known that mature CD83 + DCs have a reduced IL-12-producing capacity, resulting mainly from their impaired responsiveness to IFN- $\gamma$, which is a cofactor in IL12 induction (Kalinski et al, 1999). Accordingly, in our study, we found that the percentage of Lin-/HLA-DR + DCs expressing IFN$\gamma$ receptor (CD119) was significantly reduced in cancer patients.
Furthermore, the percentage of DCs expressing IL-12 was directly correlated with the percentage of DCs expressing CD119 on their surface. The reduced capacity of PB DCs to express IL-12 upon LPS in vitro stimulation in our breast cancer patients was specific for this cytokine, and could not be ascribed to a general hyporesponsiveness of these cells to LPS. In fact, LPS-induced upregulation of CD80, CD86 and CD83, and the expression of IL-10 were similar in cancer patients and healthy controls.

A perturbation of the cytokine network characterised by low levels of IL-12 and normal or high levels of IL-10 has been previously reported in patients with neoplasms of various organs (O'Hara et al, 1998; Jacobs et al, 1998; Merendino et al, 1999); it has been suggested that this imbalance in IL-12 and IL-10 levels could explain the shift from type 1 to type 2 cytokine production by $\mathrm{T}$ lymphocytes known to occur in cancer patients (Elässer-Beile et al, 1993; Clerici et al, 1994; Clerici et al, 1997, 1998). Actually, we found that T-helper lymphocytes from our cancer patients were polarised towards the Th2 phenotype, suggesting that altered production of regulatory cytokines by DCs may affect adaptive immune responses.

In summary, our results seem to suggest that breast cancer affects DC maturation following two pathways. The first one could affect early stages of DC differentiation and could be responsible for the increased frequency of CD34 + cells and decreased number of Lin-/HLA-DR + DCs observed in the peripheral blood of breast cancer patients (Almand et al, 2000). The second pathway could affect later stages of DC differentiation, and could be responsible for the shift to a mature-like phenotype and for the impaired IL-12 production by PB DCs. We suggest that these two mechanisms could concomitantly act in breast cancer to prevent the establishment of an effective antitumour immune response.

\section{ACKNOWLEDGEMENTS}

This work was supported in part by grants from Ministero dell'Università e della Ricerca Scientifica e Tecnologica, cofinanziamento 1999 (12-2-5182010-5). We thank Professor Claudio Stefanelli, Dipartimento di Biochimica, Università degli Studi di Bologna, for measurement of plasma levels of spermine.

\section{REFERENCES}

Almand B, Resser JR, Lindman B, Nadaf S, Clark JI, Kwon ED, Carbone DP, Gabrilovich DI (2000) Clinical significance of defective dendritic cell differentiation in cancer. Clin Cancer Res 6: 1755-1766

Almeida J, Bueno C, Alguero MC, Sanchez ML, Canizo MC, Fernandez ME, Vaquero JM, Laso FJ, Escribano L, San Miguel JF, Orfao A (1999) Extensive characterization of the immunophenotype and pattern of cytokine production by distinct subpopulations of normal human peripheral blood MHC+/lineage- cells. Clin Exp Immunol 118: 392 - 401

Arpinati M, Green CL, Heimfeld S, Heuser JE, Anasetti C (2000) Granulocyte-colony stimulating factor mobilizes $\mathrm{T}$ helper 2-inducing dendritic cells. Blood 95: 2484-2490

Bell D, Chomarat P, Broyles D, Netto G, Harb GM, Lebecque S, Valladeau J, Davoust J, Palucka KA, Banchereau J (1999) In breast carcinoma tissue, immature dendritic cells reside within the tumour, whereas mature dendritic cells are located in peritumoral areas. J Exp Med 190: $1417-1425$

Bellone M, Iezzi G, Rovere P, Galati G, Ronchetti A, Protti MP, Davoust J, Rugarli C, Manfredi AA (1997) Processing of engulfed apoptotic bodies yields T cell epitopes. J Immunol 159: 5391-5399

Bender A, Sapp M, Schuler G, Steinman RM, Bhardwaj N (1996) Improved methods for the generation of dendritic cells from nonproliferating progenitors in human blood. J Immunol Methods 196: 121-135

Bueno C, Almeida J, Alguero MC, Sanchez ML, Vaquero JM, Laso FJ, San Miguel JF, Escribano L, Orfao A (2001) Flow cytometric analysis of cytokine production by normal human peripheral blood dendritic cells and monocytes: comparative analysis of different stimuli, secretionblocking agents and incubation periods. Cytometry 46: 33-40

Cella M, Scheidegger D, Palmer-Lehmann K, Lane P, Lanzavecchia A, Alber G (1996) Ligation of CD40 on dendritic cells triggers production of high levels of interleukin-12 and enhances $\mathrm{T}$ cell stimulatory capacity: $\mathrm{T}-\mathrm{T}$ help via APC activation. J Exp Med 184: 747-752

Chaisiri P, Harper ME, Griffith K (1979) Plasma spermine concentrations of patients with benign and malignant tumors of the breast and prostate. Clin Chim Acta 92: 273-282

Clerici M, Ferrario E, Trabattoni D, Viviani S, Bonfanti V, Venzon DJ, Clerici E, Shearer GH, Villa ML (1994) Multiple defects of T helper cell function in newly diagnosed patients with Hodgkin's disease. Eur J Cancer 30: $1464-1470$

Clerici M, Merola M, Ferrario E, Trabattoni D, Villa ML, Stefanon B, Venzon DJ, Shearer GH, De Palo G, Clerici E (1997) Cytokine production patterns in cervical intraepithelial neoplasia: association with human papilomavirus infection. J Natl Cancer Inst 89: 245-250

Clerici M, Shearer GM, Clerici E (1998) Cytokine dysregulation in invasive cervical carcinoma and other human neoplasias: time to consider the TH1/TH2 paradigm. J Natl Cancer Inst 90: 261-262

Croft M, Duncan DD, Swain SL (1992) Response of naive antigen-specific CD4+ $\mathrm{T}$ cells in vitro: characteristics and antigen presenting requirements. J Exp Med 176: $1431-1437$

Della Bella S, Molteni M, Mocellin C, Fumagalli S, Bonara P, Scorza R (2001) Novel mode of action of iloprost: in vitro down-regulation of 
endothelial cell adhesion molecules. Prostaglandins Other Lipid Mediat 65: $73-83$

Dong R, Cwynarskj K, Entwistle A, Marelli-Berg F, Dazzi F, Simpson E, Goldman JM, Melo JV, Lechler RI, Bellantuono I, Ridley A, Lombardi G (2003) Dendritic cells from CML patients have altered actin organization, reduced antigen processing, and impaired migration. Blood 101: $3560-$ 3567

Elässer-Beile U, von Kleist S, Sauther W, Gallati H, Schulte Mönting J (1993) Impaired cytokine production in whole blood cell cultures of patients with gynaecological carcinomas in different clinical stages. $\mathrm{Br} J$ Cancer 68: $32-36$

Gabrilovich DI, Chen HL, Girgis KR, Cunningham HT, Meny GM, Nadaf S, Kavanaugh D, Carbone DP (1996) Production of vascular endothelial growth factor by human tumours inhibits the functional maturation of dendritic cells. Nat Med 2: 1096-1103

Gabrilovich DI, Ishida T, Nadaf S, Ohm JE, Carbone DP (1999) Antibodies to vascular endothelial growth factor enhance the efficacy of cancer immunotherapy by improving endogenous dendritic cell function. Clin Cancer Res 5: 2963-2970

Garrity T, Pandit R, Wright MA, Benefield J, Keni S, Young MRI (1997) Increased presence of CD34+ cells in the peripheral blood of head and neck cancer patients and their differetiation into dendritic cells. Int $J$ Cancer 73: 663-669

Harizi H, Juzan M, Pitard V, Moreau JF, Gualde M (2002) Cyclooxygenase2 -issued prostaglandin $\mathrm{E}_{2}$ enhances the production of endogenous IL-10, which down-regulates dendritic cells functions. J Immunol 168: 22552263

Haskò G, Kuhel DG, Marton A, Nemeth ZH, Deitch EA, Szabò C (2000) Spermine differentially regulates the production of interleukin-12 p40 and interleukin-10 and suppresses the release of the T helper 1 cytokine interferon- $\gamma$. Shock 14: $144-149$

Ishida T, Oyama T, Carbone DP, Gabrilovich DI (1998) Defective function of Langerhans cells in tumor-bearing animals is the result of defective maturation from hemopoietic progenitors. J Immunol 161: 4842 - 4851

Jacobs N, Giannini SL, Doyen J, Baptista A, Moutschen M, Boniver J, Delvenne P (1998) Inverse modulation of IL-10 and IL-12 in the blood of women with preneoplastic lesions of the uterine cervix. Clin Exp Immunol 111: 219-224

Kalinski P, Schuitemaker JHN, Hilkens CMU, Wierenga EA, Kapsenberg ML (1999) Final maturation of dendritic cells is associated with impaired responsiveness to IFN- $\gamma$ and to bacterial IL-12 inducers: decreased ability of mature dendritic cells to produce IL-12 during the interaction with Th cells. J Immunol 162: $3231-3236$

Kiertscher SM, Luo J, Dubinett SM, Roth MD (2000) Tumors promote altered maturation and early apoptosis of monocyte-derived dendritic cells. J Immunol 164: 1269-1276

Knapp HR, Oelz O, Robert LJ, Sweetman BJ, Oates JA, Reed PW (1977) Ionophores stimulate prostaglandin and thromboxane biosynthesis. Proc Natl Acad Sci USA 74: 4251-4255

Krug A, Towarowski A, Britsch S, Rothenfusser S, Hornung V, Bals R, Giese T, Engelmann H, Endres S, Krieg AM, Hartmann G (2001) Toll-like receptor expression reveals CpG DNA as a unique microbial stimulus for plasmacytoid dendritic cells which synergizes with CD40 ligand to induce high amounts of IL-12. Eur J Immunol 31: 3026-3037

Larsson M, Fonteneau JF, Bhardwaj N (2001) Dendritic cells resurrect antigens from dead cells. Trends Immunol 22: 141-148

Lathers DM, Lubbers E, Beal NM, Wright MA, Young MR (1999) Cultures derived from peripheral blood CD34+ progenitor cells of head and neck cancer patients and from cord blood are functionally different. Hum Immunol 60: 1207-1215

Lechmann M, Berchtold S, Hauber J, Steinkasserer A (2002) CD83 on dendritic cells: more than just a marker for maturation. Trends Immunol 23: $273-275$
Lee SH, Kim SO, Lee HD, Chung BC (1998) Estrogens and polyamines in breast cancer: their profiles and values in disease staging. Cancer Lett 133: $47-56$

Liu YJ, Kanzler H, Soumelis V, Gilliet M (2001) Dendritic cell lineage, plasticity and cross-regulation. Nat Immunol 2: 585-589

Marchesini G, Checchia GA, Stefanelli C, Bianchi G, Fabbri A, Zoli M, Caldera CH, Pisi E (1992) Polyamine plasma levels and liver regeneration following partial hepatic resection in man. J Hepatol 16: 159-164

Menetrier-Caux C, Montmain G, Dieu MC, Bain C, Favrot MC, Caux C, Blay JY (1998) Inhibition of the differentiation of dendritic cells from CD34+ progenitors by tumor cells: role of interleukin- 6 and macrophage colonystimulating factor. Blood 92: 4778-4791

Merendino RA, Gangemi S, Misefari A, Arena A, Capozza AB, Chillemi S, D'Ambrosio FP (1999) Interleukin-12 and interleukin-10 production by mononuclear phagocytic cells from breast cancer patients. Immunol Lett 68: $355-358$

Mohty M, Jarrossay D, Lafage-Pochitaloff M, Zandotti C, Briere F, de Lamballeri XN, Isnardon D, Sainty D, Olive D, Gaugler B (2001) Circulating blood dendritic cells from myeloid leukemia patients display quantitative and cytogenetic abnormalities as well as functional impairment. Blood 98: 3750-3756

O’Hara RJ, Greenman J, MacDonald AW, Gaskell KM, Topping KP, Duthie GS, Kerin MJ, Lee PW, Monson JR (1998) Advanced colorectal cancer is associated with impaired interleukin 12 and enhanced interleukin 10 production. Clin Cancer Res 4: 1943-1948

Reid SD, Penna G, Adorini L (2000) The control of T cell responses by dendritic cell subsets. Curr Opin Immunol 12: 114-121

Rescigno M, Granucci F, Ricciardi-Castagnoli P (1999) Dendritic cells at the end of the millenium. Immunology 77: 404-410

Rissoan MC, Soumelis V, Kadowaki N, Grouard G, Briere F, de Waal Malefyt R, Liu YJ (1999) Reciprocal control of T helper cell and dendritic cell differentiation. Science 283: 1183-1186

Robinson SP, Patterson S, English N, Davies D, Knight SC, Reid CDL (1999) Human peripheral blood contains two distinct lineages of dendritic cells. Eur J Immunol 29: 2769-2778

Rostaing L, Tkaczuk J, Durand M, Peres C, Durand D, De Preval C, Ohayon E, Abbal M (1999) Kinetics of intracytoplasmatic Th1 and Th2 cytokine production assessed by flow cytometry following in vitro activation of peripheral blood mononuclear cells. Cytometry 35: 318-328

Sallusto F, Cella M, Danieli C, Lanzavecchia A (1995) Dendritic cells use macropinocytosis and the mannose receptor to concentrate macromolecules in the major histocompatibility complex class II compartment: down-regulation by cytokines and bacterial products. J Exp Med 182: $389-400$

Schultz J, Nadler L, Gribben J (1996) B7-mediated costimulation and the immune response. Blood Rev 10: 111-127

Seiler N, Atanassov CL (1994) The natural polyamines and the immune system. Prog Drug Res 43: 87-141

Shortman K, Liu YJ (2002) Mouse and human dendritic cell subsets. Nat Rev Immunol 2: $151-161$

Sobin LH, Witterkind C (eds) (2002) TNM Classification of Malignant Tumours, pp. 131-141. New York:Wiley.

Upham JW, Lundahl J, Liang H, Denburg JA, O'Byrne PM, Snider DP (2000) Simplified quantitation of myeloid dendritic cells in peripheral blood using flow cytometry. Cytometry 40: $50-59$

Zhang M, Caragine T, Wang H, Cohen PS, Botchkina G, Soda K, Bianchi H, Ulrich P, Cerami A, Sherry B, Tracey KJ (1997) Spermine inhibits proinflammatory cytokine synthesis in human mononuclear cells: a counter-regulatory mechanism that restrains the immune response. J Exp Med 185: $1759-1768$

Zhou LJ, Tedder TF (1995) Human blood dendritic cells selectively express CD83, a member of the immunoglobulin superfamily. J Immunol 154: $3821-3835$ 